\title{
Impact of 1-methylcyclopropene and controlled atmosphere storage on polyamine and 4-aminobutyrate levels in "Empire" apple fruit
}

\section{Kristen L. Deyman, Carolyne J. Brikis, Gale G. Bozzo and Barry J. Shelp*}

Department of Plant Agriculture, University of Guelph, Guelph, ON, Canada

\section{Edited by:}

Antonio F. Tiburcio, Universitat de Barcelona, Spain

\section{Reviewed by:}

Subhash C. Minocha, University of New Hampshire, USA

Manchikatla Venkat Rajam, University of Delhi South Campus, India

\section{*Correspondence:}

Barry J. Shelp, Department of Plant Agriculture, Bovey Building, University of Guelph, 50 Stone Road East, Guelph, ON N1G 2W1, Canada e-mail:bshelp@uoguelph.ca
1-Methylcyclopropene (1-MCP) delays ethylene-meditated ripening of apple (Malus domestica Borkh.) fruit during controlled atmosphere (CA) storage. Here, we tested the hypothesis that 1-MCP and CA storage enhances the levels of polyamines (PAs) and 4-aminobutyrate (GABA) in apple fruit. A 46-week experiment was conducted with "Empire" apple using a split-plot design with four treatment replicates and $3^{\circ} \mathrm{C}, 2.5 \mathrm{kPa} \mathrm{O}$, and 0.03 or $2.5 \mathrm{kPa}$ $\mathrm{CO}_{2}$ with or without $1 \mu \mathrm{L} \mathrm{L}{ }^{-1} 1$-MCP. Total PA levels were not elevated by the 1-MCP treatment. Examination of the individual PAs revealed that: (i) total putrescine levels tended to be lower with 1-MCP regardless of the $\mathrm{CO}_{2}$ level, and while this was mostly at the expense of free putrescine, large transient increases in soluble conjugated putrescine were also evident; (ii) total spermidine levels tended to be lower with 1-MCP, particularly at $2.5 \mathrm{KPa} \mathrm{CO}_{2}$, and this was mostly at the expense of soluble conjugated spermidine; (iii) total spermine levels at $2.5 \mathrm{kPa} \mathrm{CO}$ tended to be lower with 1-MCP, and this was mostly at the expense of both soluble and insoluble conjugated spermine; and (iv) total spermidine and spermine levels at $0.03 \mathrm{kPa}$ were relatively unaffected, compared to $2.5 \mathrm{kPa} \mathrm{CO}$, but transient increases in free spermidine and spermine were evident. These findings might be due to changes in the conversion of putrescine into higher PAs and the interconversion of free and conjugated forms in apple fruit, rather than altered $S$-adenosylmethionine availability. Regardless of 1-MCP and $\mathrm{CO}_{2}$ treatments, the availability of glutamate showed a transient peak initially, probably due to protein degradation, and this was followed by a steady decline over the remainder of the storage period which coincided with linear accumulation of GABA. This pattern has been attributed to the stimulation of glutamate decarboxylase activity and inhibition of GABA catabolism, rather than a contribution of PAs to GABA production.

Keywords: abiotic stress, apple fruit, controlled atmosphere storage, 4-aminobutyrate (GABA), 1-methylcyclopropene (1-MCP), high performance liquid chromatography, polyamines

\section{INTRODUCTION}

Over the last decade, 1-methylcyclopropene (1-MCP) has been adopted by the apple industry as a means of delaying ethylenemediated fruit ripening and senescence, especially in combination with storage under controlled atmosphere (CA) conditions (i.e., $0-3^{\circ} \mathrm{C}, 2-2.5 \mathrm{kPa} \mathrm{O}_{2}, 2-4 \mathrm{kPa} \mathrm{CO}$; DeEll et al., 2008; Fawbush etal., 2008; Watkins, 2008). 1-MCP inhibits ethylene binding and production in apple fruit held at ambient or chilling temperature, and reduces the expression of genes responsible for ethylene biosynthesis (Dal Cin et al., 2006; Pang et al., 2006; Vilaplana et al., 2007; Figure 1). Under commercial CA conditions, these findings are accompanied by a decline in the level of 1aminocyclopropane-1-carboxylic acid (ACC), and the level of its precursor $S$-adenosylmethionine (SAM) is not directly linked to the rate of ethylene production and does not appear to be limiting (Bulens et al., 2012).

$S$-adenosylmethionine is essential for conversion of putrescine (Put) into the higher polyamines (PAs) spermidine (Spd) and spermine (Spm), as well the production of ethylene (Figure 1). During the ripening of a bulky fruit such as tomato, there is an inverse relationship between the production of higher PAs and ethylene (Lasanajak et al., 2014), 1-MCP treatment inhibits autocatalytic ethylene production without affecting SAM levels (Van de Poel etal., 2013), and decreased levels of ethylene in RNAi-1-aminocyclpropane-1-carboxylate synthase fruits enhance PA levels and upregulate PA biosynthesis genes (Gupta etal., 2013). Research with non-bulky fruits such as rice grain also suggests interaction between PAs and ethylene in regulating plant growth and in response to environmental stress (Chen et al., 2013). Notably, there is a transient increase in the level of Put only, and no changes in the level of Spd, Spm, or total PAs in apple fruit stored at $24^{\circ} \mathrm{C}$, even though the expression of only one of two SAM decarboxylases (SAMDCs) is repressed (Pang et al., 2006).

During CA storage 4-aminobutyrate (GABA) accumulates in apple fruit (Deewatthanawong and Watkins, 2010; Lee etal., 2012; Trobacher etal., 2013a), but it is uncertain whether this 


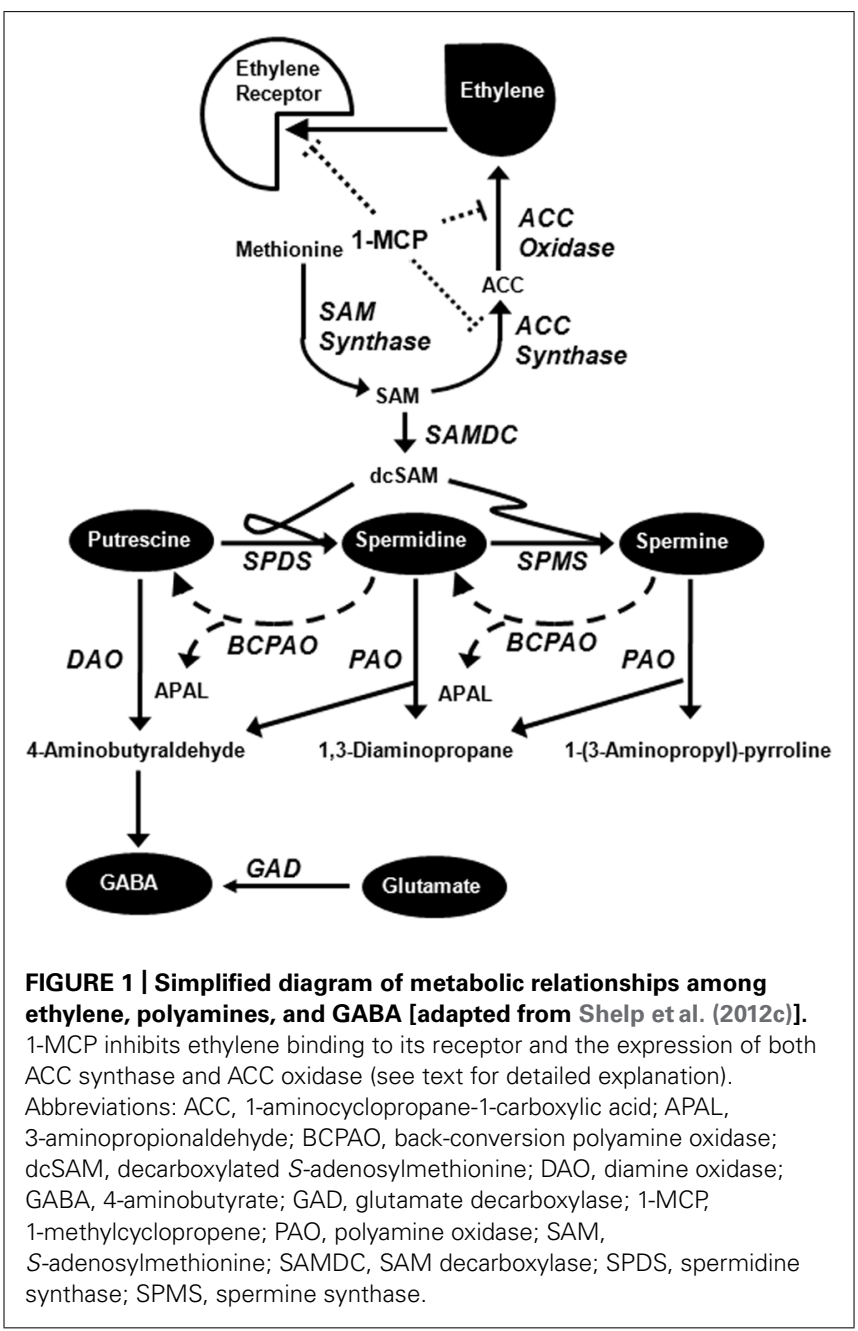

GABA is derived from PAs or glutamate (Shelp et al., 2012c; Figure 1). Notably, the levels of both PAs and GABA can be stimulated by abiotic stresses such as chilling, $\mathrm{O}_{2}$ deficiency and elevated $\mathrm{CO}_{2}$, conditions that are the basis of CA storage (Alcázar et al., 2010; Bitrián et al., 2012; Shelp et al., 2012a,b,c; Trobacher et al., 2013a).

Here, we tested the hypothesis that $1-\mathrm{MCP}$ and CA storage enhances the levels of PAs and GABA in apple fruit imposed by abiotic stresses associated with CA storage. Since 1-MCP has been shown to increase the incidence of $\mathrm{CO}_{2}$-induced physiological injury in "Empire" fruit during CA storage (Watkins, 2006; Fawbush et al., 2008; Jung and Watkins, 2011), we utilized two levels of $\mathrm{CO}_{2}(2.5$ and $0.03 \mathrm{kPa})$.

\section{MATERIALS AND METHODS APPLE SOURCE AND CONTROLLED ATMOSPHERE STORAGE TRIALS}

Sixteen boxes $(\sim 20 \mathrm{~kg}$ each) of apple (Malus domestica Borkh. $\mathrm{cv}$. Empire) fruit were harvested in the morning from a commercial orchard within $15 \mathrm{~km}$ of Simcoe, Ontario on 29 September 2011, and immediately transported to our post-harvest facility at the University of Guelph. On arrival, four fruit were randomly chosen, frozen as quickly as is practical in liquid $\mathrm{N}_{2}$ and stored at $-80^{\circ} \mathrm{C}$ for future metabolite analysis. Then the boxes were divided into two treatments without or with $1 \mu \mathrm{L} \mathrm{L}^{-1}$ 1-MCP (SmartFresh ${ }^{S M}$, AgroFresh Inc., Spring House, PA, supplied in sealed polybags) and stored at approximately $23^{\circ} \mathrm{C}$ for 1 day.

A split-plot design was used to eliminate the possibility of chamber effects. Fruit were stored in two random chambers that were set at $3^{\circ} \mathrm{C}$; within each chamber, two rooms were supplied with $2.5 \mathrm{kPa} \mathrm{O}_{2}$ and either $2.5 \mathrm{kPa}$ or $0.03 \mathrm{kPa} \mathrm{CO}_{2}$, giving a total of four rooms, each containing fruit treated without or with 1MCP. The four rooms in each chamber were treated as biological replicates in this nested design.

About 90 fruit were stored in individual boxes in the CA rooms, which were sealed and flushed with $99 \mathrm{kPa} \mathrm{N} 2$. When the $\mathrm{O}_{2}$ concentration declined to $2.5 \mathrm{kPa}, \mathrm{N}_{2}$ flushing was replaced with $\mathrm{CO}_{2}$ until 2.5 or $0.03 \mathrm{kPa} \mathrm{CO}_{2}$ was achieved. Four fruit were collected from each box at eight different time points over the storage period (17 days, and $4,8,10,14,23,33$, and 46 weeks) following harvest, frozen in liquid $\mathrm{N}_{2}$ and stored at $-80^{\circ} \mathrm{C}$ prior to metabolite analysis. Fruit were also collected for assessment of fruit quality, but these data will be reported elsewhere.

\section{METABOLITE COMPOSITION OF WHOLE APPLE FRUIT Polyamine analysis}

For each treatment replicate, four whole frozen apples were cryogenically pulverized, taking care to ensure that the apple tissue did not thaw during the procedure (Trobacher et al., 2013a). PAs were essentially extracted and analyzed as described by Smith and Davies (1985) and Shiozaki et al. (2000). Briefly, $100 \mathrm{mg}$ of fine frozen powder (comprised of $25 \mathrm{mg}$ from each of the four apple subsamples in each treatment replicate) was homogenized in cold $5 \%$ perchloric acid (PCA, $100 \mathrm{mg} \mathrm{mL}^{-1}$ ), placed on ice for $30 \mathrm{~min}$ and then spiked with $10 \mu \mathrm{L}$ of the internal standard 1,6 hexanediamine $\left(0.25 \mathrm{nmol} \mu \mathrm{L}^{-1}\right.$; Fisher Scientific, Whitby, ON, Canada). The sample was centrifuged for $20 \mathrm{~min}$ at $14,000 \mathrm{~g}$ at room temperature, and the supernatant was transferred to a $2-\mathrm{mL}$ microfuge tube and maintained on ice for $30 \mathrm{~min}$. The pellet was extracted again in $1 \mathrm{~mL}$ of 5\% PCA and treated as above. For analysis of free and conjugated soluble polyamines, the two supernatants were combined and dried in vacuo at $60^{\circ} \mathrm{C}$ or under a stream of filtered air at room temperature, then redissolved in $0.4 \mathrm{~mL}$ of $5 \%$ PCA. One half of this extract was transferred to a 5-mL amber reacti-vial and derivatized for analysis of free PAs as described below. The remaining $0.2 \mathrm{~mL}$ was hydrolyzed with $\mathrm{HCl}$ as described below before derivatization. The soluble conjugated soluble polyamines were estimated as the difference between the hydrolyzed and original supernatants.

The final pellet was resuspended in $0.2 \mathrm{~mL}$ of $1 \mathrm{M} \mathrm{NaOH}$ and centrifuged for $5 \mathrm{~min}$ at 10,000 $\mathrm{g}$. The supernatant was transferred to a $2-\mathrm{mL}$ amber Eppendorf tube and hydrolyzed with $0.2 \mathrm{~mL}$ of $12 \mathrm{M} \mathrm{HCl}$ at room temperature for $18 \mathrm{~h}$. The sample was then dried as above, resuspended in $0.2 \mathrm{~mL}$ of $5 \%$ PCA and derivatized for analysis of conjugated insoluble polyamines.

A $0.6 \mathrm{~mL}$ aliquot of dansyl chloride (Sigma Aldrich, Oakville, $\mathrm{ON}$, Canada) in acetone $\left(7.5 \mathrm{mg} \mathrm{mL}^{-1}\right.$ acetone) was added to a $0.2-\mathrm{mL}$ aliquot of the various PCA extracts. Then $0.3 \mathrm{~mL}$ of a 
saturated sodium carbonate solution was added with brief vortexing to give a $\mathrm{pH}$ of 10 . The mixture was placed in a $60^{\circ} \mathrm{C}$ waterbath for $30 \mathrm{~min}$ (Gennaro et al., 1988). A 0.1-mL aliquot of proline $\left(0.1 \mathrm{~g} \mathrm{~mL}^{-1}\right.$; Sigma Aldrich) was added to the solution to remove excess dansyl chloride, and then the mixture was incubated in the dark for $15 \mathrm{~min}$ at room temperature. Dansylated PAs were extracted from the mixture by adding $0.5 \mathrm{~mL}$ toluene (Fisher Scientific, Whitby, ON, Canada) and vortexing for $1 \mathrm{~min}$. Then, $0.4 \mathrm{~mL}$ was taken from the organic layer and dried under filtered air for $30 \mathrm{~min}$. The dry residue was dissolved in $0.2 \mathrm{~mL}$ methanol and stored at $4^{\circ} \mathrm{C}$ in the dark for up to 2 weeks.

Dansylated PAs were passed through 0.45 um syringe filter and $20-\mu \mathrm{L}$ aliquots injected onto a reverse-phase column (Agilent Zorbax ODS $5 \mu \mathrm{m}, 4.6 \mathrm{~mm} \times 150 \mathrm{~mm}$ ) linked to an Agilent 1100 HPLC system (Allan and Shelp, 2006). Initially, 60\% methanol was provided for $4 \mathrm{~min}$ at a flow rate of $1.5 \mathrm{~mL} \mathrm{~min}^{-1}$, followed by a linear increase to $95 \%$ methanol over 10 min and then $95 \%$ methanol for a further $5 \mathrm{~min}$. The PAs were quantified with a fluorescence detector set at excitation and emission wavelengths of 254 and $500 \mathrm{~nm}$, respectively (Gennaro et al., 1988). Although other peaks might appear on the chromatogram, they eluted before all dansylated PAs of interest, allowing for good resolution of Put $(\mathrm{RT}=12.6 \mathrm{~min}), 1,6$ hexanediamine $(\mathrm{RT}=13.8 \mathrm{~min})$, Spd $(\mathrm{RT}=16.4 \mathrm{~min})$, and $\mathrm{Spm}(\mathrm{RT}=18.5 \mathrm{~min})$. Each treatment replicate was considered to be the average of the four subsamples.

The linearity of the standard curves up to 120 pmol for Put, Spd, Spm and 1,6 hexanediamine (Sigma Aldrich, Oakville, ON, Canada) was not affected by the addition of frozen apple powder tissue to the extraction procedure. The recovery of the internal standard across apple samples was approximately $60 \%$; all samples were corrected for the actual loss during preparation. Furthermore, reverse-phase HPLC analysis of the PA standards and apple samples showed baseline separation of all PAs of interest. For routine analysis, a suite of external standards ( 80 pmol each) was run every sixth sample. The detection limit for the overall method was approximately $0.10 \mathrm{nmol} g^{-1}$ fresh mass (FM).

\section{Amino acid analysis}

The amino acid composition of each apple was determined essentially as described previously (Allan and Shelp, 2006). Briefly, $1 g$ of the fine frozen powder was ground in four volumes of $30 \mathrm{~g} \mathrm{~L}^{-1}$ sulfosalicylic acid using a chilled mortar and pestle and fine silica sand, and $1.0 \mathrm{~mL}$ of the solution was centrifuged. The supernatant was adjusted to neutrality with $\mathrm{NaOH}$, and then passed through a $0.45-\mu \mathrm{m}$ syringe filter prior to on-line derivatization with $o$-phthalaldehyde. Aliquots $(0.5 \mu \mathrm{L})$ of the supernatant were analyzed by reverse-phase HPLC. Each treatment replicate was considered to be the average of the four subsamples analyzed and each mean was the average of four treatment replicates. A suite of external amino acid standards ( 125 pmol each) derived from protein hydrolysate and the individual amino acids GABA, asparagine and glutamine were run every sixth sample.

\section{Statistical analysis of data}

All statistical analyses were conducted using SAS 9.2 at the $\alpha=0.05$ level (SAS Institute Inc., Cary, NC, USA). Replicate room effects were analyzed using analysis of variances (ANOVAs; proc mixed method), which partitioned variance into the fixed effects (1-MCP, temperature, $\mathrm{CO}_{2}$, storage time) and their interactions, and the random effect of chambers. In cases where interactions were significant $(P \leq 0.05)$, treatment means were compared within weeks (slice option) over the period from 17 days to 46 weeks using a Fisher's protected least significant difference test. For experiments where interactions were significant $(P \leq 0.05)$, data were pooled across repeated measures to determine differences among treatments and over storage period using the Tukey's test. All data were arcsine square root transformed to ensure a normal distribution of variance and the treatment means were back-transformed for presentation.

\section{RESULTS}

Total apple PAs consisted of free, soluble conjugated, and insoluble conjugated forms, with free and soluble conjugated forms being at much higher concentrations than the insoluble conjugated forms (Figures 2A-D). The concentrations of all forms fluctuated considerably during the 1-MCP treatment and the initial collection periods at 17 days and 4 weeks, but were much steadier from 8 to 46 weeks. Therefore, statistical analysis of the main effects and interactions was conducted for the entire treatment period, whereas detailed comparisons between the 1-MCP treatments were made over the 8-46 week period. Furthermore, the total PAs were comprised primarily of total Put and total Spd, followed by total Spm (Figures 3-5, panel A). The concentrations of individual PAs consisted mainly of the free form, followed closely by the soluble conjugated form, and more distantly by the insoluble conjugated form (Figures 3-5, panels B-D). Notably, the concentrations of the free forms tended to fluctuate less than the conjugated forms.

The concentrations of total PAs showed significant storage time, $\mathrm{CO}_{2}$ and 1-MCP main effects, as well as storage time $\times \mathrm{CO}_{2}, 1$ $\mathrm{MCP} \times \mathrm{CO}_{2}$, and storage time $\times \mathrm{CO}_{2} \times 1-\mathrm{MCP}$ interactions ( $P \leq 0.05$, ANOVA table not shown). During the period from 8 to 46 weeks, the total PA concentrations in 1-MCP-treated fruit at $2.5 \mathrm{kPa} \mathrm{CO} 2$ were, with the exception of 8 and 23 weeks, 33-61\% of those in control fruit (i.e., not treated with 1-MCP), whereas at $0.03 \mathrm{kPa} \mathrm{CO} 2$ they were $29-39 \%$ of those at 33 and 46 weeks (Figure 2A). The concentrations of total free PAs showed significant storage time and $\mathrm{CO}_{2}$ main effects, as well as storage time $\times 1-\mathrm{MCP}$, and storage time $\times 1-\mathrm{MCP} \times \mathrm{CO}_{2}$ interactions ( $P \leq 0.05$, ANOVA table not shown). At $2.5 \mathrm{kPa} \mathrm{CO}_{2}$ the total free PA concentrations in 1-MCP-treated fruit were $49-51 \%$ of those in control fruit at 23 and 33 weeks, whereas at $0.03 \mathrm{kPa} \mathrm{CO}_{2}$ they were, with the exception of weeks 23 and 33, 27-52\% of those in control fruit (Figure 2B). The concentrations of total soluble conjugated PAs showed significant $\mathrm{CO}_{2}$ and 1-MCP main effects, as well as $\mathrm{CO}_{2} \times 1-\mathrm{MCP}$, storage time $\times \mathrm{CO}_{2} \times 1-\mathrm{MCP}$ interactions ( $P \leq 0.05$, ANOVA table not shown). At $2.5 \mathrm{kPa} \mathrm{CO}_{2}$, the concentrations of total soluble conjugated PAs in 1-MCP-treated fruit were similar to those in control fruit, whereas at $0.03 \mathrm{kPa} \mathrm{CO}_{2}$ they were $6 \%$ of that in the control at 33 weeks (Figure 2C). The concentrations of total insoluble conjugated PAs showed significant $\mathrm{CO}_{2}$ and 1-MCP main effects, and storage time $\times 1-\mathrm{MCP}$, $\mathrm{CO}_{2} \times 1$-MCP interactions $(P \leq 0.05$, ANOVA table not shown $)$. 

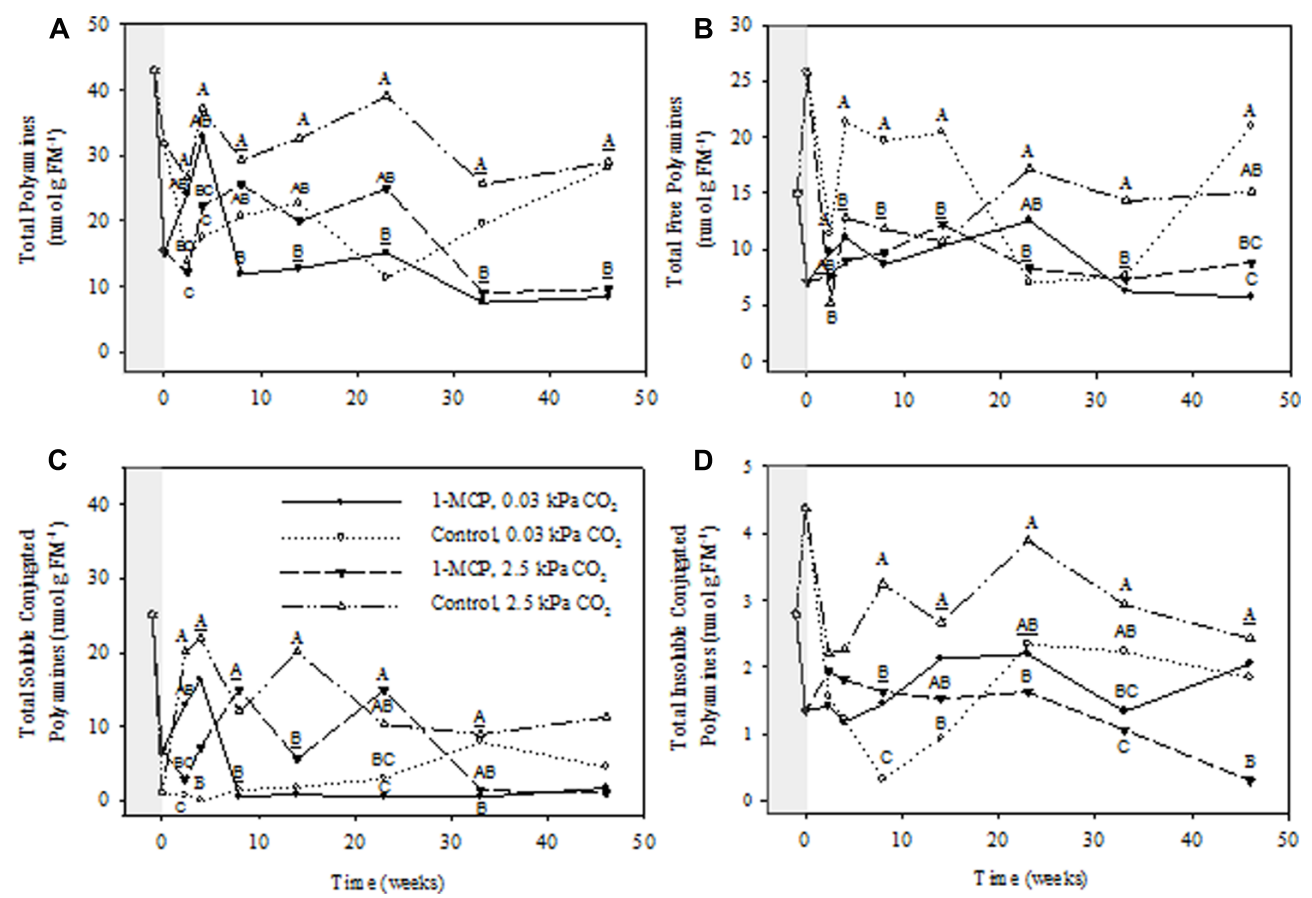

FIGURE 2 | Effects of 1-MCP and elevated $\mathrm{CO}_{2}$ on total (A), total free (B), total soluble conjugated (C), and total insoluble conjugated (D) polyamines in "Empire" fruit during controlled atmosphere storage. With the exception of the beginning and end of $1-\mathrm{MCP}$ treatment ( -1 day to 0 week, the shaded area), all data are mean estimates of four storage replicates. Different letter groupings indicate significant differences between treatments within weeks $(P \leq 0.05)$. Underlined letters indicate a shared letter for overlapping data; where letters are absent at a time point, there were no significant differences.
At $2.5 \mathrm{kPa} \mathrm{CO}$ the concentrations of total insoluble conjugated PA concentrations in 1-MCP- treated fruit were, with the exception of week $14,13-57 \%$ of those in control fruit, whereas at $0.03 \mathrm{kPa}$ $\mathrm{CO}_{2}$ they were $130-350 \%$ greater at 8 and 14 weeks (Figure 2D).

The concentrations of total Put displayed significant $\mathrm{CO}_{2}$ main effects, but no interactions ( $P \leq 0.05$, ANOVA table not shown). The total Put concentrations at 2.5 and $0.03 \mathrm{kPa} \mathrm{CO}_{2}$ in 1-MCPtreated fruit were $41-44 \%$ and $32-37 \%$ of those in control fruit at 8,33 , and 46 weeks and at 8, 14, and 33 weeks, respectively (Figure 3A). There were significant storage time and $\mathrm{CO}_{2}$ main effects on the concentrations of free Put, as well as storage time $\times \mathrm{CO}_{2} \times 1-\mathrm{MCP}$ interaction $(P \leq 0.05$, ANOVA table not shown). At $2.5 \mathrm{kPa} \mathrm{CO}$ the free Put concentrations in 1-MCPtreated fruit were $25-44 \%$ of those in control fruit at 23,33 , and 46 weeks, whereas at $0.03 \mathrm{kPa} \mathrm{CO} 2$ they were, with the exception of week 23, 13-40\% of the controls (Figure 3B). The concentrations of soluble conjugated Put showed significant 1-MCP and $\mathrm{CO}_{2}$ main effects, as well as storage time $\times 1-\mathrm{MCP}$ and storage time $\times \mathrm{CO}_{2} \times 1-\mathrm{MCP}$ interactions $(P \leq 0.05$, ANOVA table not shown). At $2.5 \mathrm{kPa} \mathrm{CO}_{2}$ the concentrations of soluble conjugated Put in 1-MCP-treated fruit were $200 \%$ greater than those in control fruit at 23 weeks, whereas at $0.03 \mathrm{kPa} \mathrm{CO}_{2}$ there were no significant differences among treatments (Figure 3C). The concentrations of insoluble conjugated Put showed significant $\mathrm{CO}_{2}$ main effects, as well as storage time $\times \mathrm{CO}_{2}$, storage time $\times 1-\mathrm{MCP}, \mathrm{CO}_{2} \times 1$ $\mathrm{MCP}$ and storage time $\times \mathrm{CO}_{2} \times 1-\mathrm{MCP}$ interactions $(P \leq 0.05$, ANOVA table not shown). At $2.5 \mathrm{kPa} \mathrm{CO} 2$ the concentrations of insoluble conjugated Put in 1-MCP-treated fruit were 3-20\% of those in control fruit at 33 and 46 weeks, whereas at $0.03 \mathrm{kPa}$ $\mathrm{CO}_{2}$ they were $490-1420 \%$ greater than controls at 8 and 14 weeks (Figure 3D).

The total Spd concentrations displayed significant storage time, $\mathrm{CO}_{2}$ and 1-MCP main effects, as well as storage time $\times \mathrm{CO}_{2}$, storage time $\times 1-\mathrm{MCP}$, and $\mathrm{CO}_{2} \times 1-\mathrm{MCP}$ interactions $(P \leq 0.05$, ANOVA table not shown). At $2.5 \mathrm{kPa} \mathrm{CO} 2$ total Spd concentrations in 1-MCP-treated fruit were $25-52 \%$ of those in control fruit at 14,33 , and 46 weeks, whereas at $0.03 \mathrm{kPa} \mathrm{CO}_{2}$ there were no significant differences between treatments (Figure 4A). Free Spd concentrations showed significant storage time, $\mathrm{CO}_{2}$, and 1-MCP main effects, as well as storage time $\times \mathrm{CO}_{2}$, storage time $\times 1-\mathrm{MCP}$, and storage time $\times \mathrm{CO}_{2} \times 1-\mathrm{MCP}$ interactions ( $P \leq 0.05$, ANOVA table not shown). At $2.5 \mathrm{kPa} \mathrm{CO}_{2}$ free Spd concentrations in 1-MCP-treated fruit were $121 \%$ greater than those in control fruit at 14 weeks, whereas at $0.03 \mathrm{kPa} \mathrm{CO}_{2}$ they were $230-350 \%$ greater at 8,23 , and 33 weeks and $49 \%$ of the control at 46 weeks (Figure 4B). The concentrations of soluble conjugated Spd displayed $\mathrm{CO}_{2}$ and 1-MCP main effects, and storage time $\times \mathrm{CO}_{2}, \mathrm{CO}_{2} \times 1-\mathrm{MCP}$ and storage time $\times \mathrm{CO}_{2} \times 1-\mathrm{MCP}$ interactions $(P \leq 0.05$, ANOVA table not shown). At $2.5 \mathrm{kPa}$ $\mathrm{CO}_{2}$ the concentrations of soluble conjugated Spd in 1-MCPtreated fruit never exceeded $4 \%$ of those at 14,33 , and 46 weeks of storage, whereas at $0.03 \mathrm{kPa} \mathrm{CO}$, they were undetectable at 33 weeks of storage (Figure 4C). The concentrations of insoluble conjugated Spd showed significant storage time and 1-MCP 

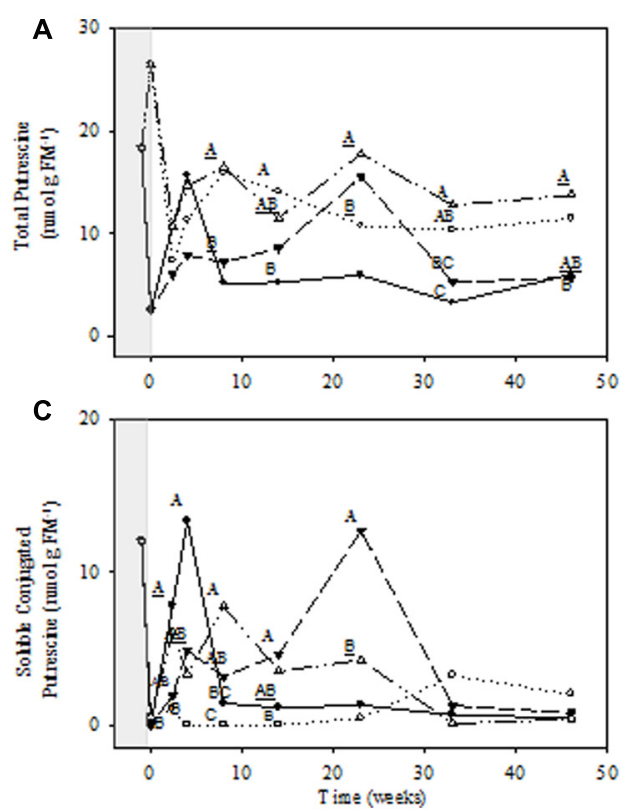

FIGURE 3 | Effects of 1-MCP and elevated $\mathrm{CO}_{2}$ on total (A), free (B), soluble conjugated (C), and insoluble conjugated (D) putrescine in

"Empire" fruit during controlled atmosphere storage. With the exception of the beginning and end of 1-MCP treatment ( -1 day to 0 week, the shaded
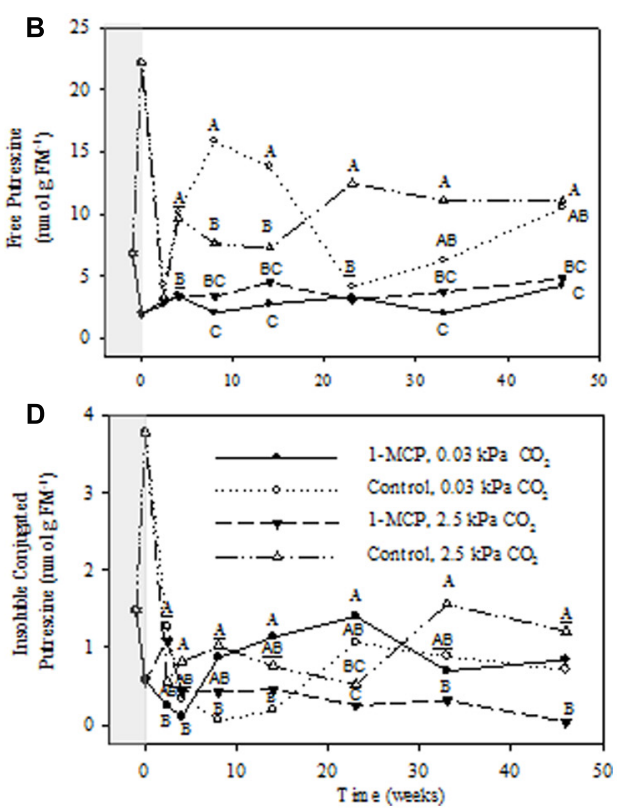

area), all data are mean estimates of four storage replicates. Different letter groupings indicate significant differences between treatments within weeks $(P \leq 0.05)$. Underlined letters indicate a shared letter for overlapping data; where letters are absent at a time point, there were no significant differences. main effects and storage time $\times 1-\mathrm{MCP}$ interactions $(P \leq 0.05$, ANOVA table not shown). At 2.5 and $0.03 \mathrm{kPa} \mathrm{CO}_{2}$, there were no significant differences between the 1-MCP treatments (Figure 4D).

The concentrations of total Spm showed significant storage time and $\mathrm{CO}_{2}$ main effects, as well as $\mathrm{CO}_{2} \times 1-\mathrm{MCP}$ and storage time $\times \mathrm{CO}_{2} \times 1-\mathrm{MCP}$ interactions $(P \leq 0.05$, ANOVA table not shown). At $2.5 \mathrm{kPa} \mathrm{CO}$ total Spm concentrations in 1-MCPtreated fruit were $140 \%$ greater than those that in control fruit at 8 weeks, but $34 \%$ of the control at 23 weeks (Figure 5A). There were no differences between treatments at $0.03 \mathrm{kPa} \mathrm{CO}_{2}$. The concentration of free Spm showed significant storage time and 1 -MCP main effects ( $P \leq 0.05$, ANOVA table not shown). At $2.5 \mathrm{kPa} \mathrm{CO}_{2}$ there was no significant differences between the treatments, whereas at $0.03 \mathrm{kPa} \mathrm{CO}$ the free Spm concentration was $260 \%$ greater in 1-MCP-treated fruit than that in control fruit at 23 weeks (Figure 5B). There were significant $\mathrm{CO}_{2}$ and 1-MCP main effects, as well as storage time $\times \mathrm{CO}_{2}, \mathrm{CO}_{2} \times 1-\mathrm{MCP}$ and storage time $\times \mathrm{CO}_{2} \times 1-\mathrm{MCP}$ interactions, for concentrations of soluble conjugated Spm ( $P \leq 0.05$, ANOVA table not shown). At $2.5 \mathrm{kPa} \mathrm{CO} 2$ the concentration of soluble conjugated $\mathrm{Spm}$ in 1-MCP-treated fruit was much greater than that in control fruit at 8 weeks, but less than $3 \%$ of those at 14 and 23 weeks, whereas at $0.03 \mathrm{kPa} \mathrm{CO}_{2}$ there were no differences between 1-MCP treatments (Figure 5C). The concentrations of insoluble conjugated Spm showed significant $\mathrm{CO}_{2}$ and 1-MCP main effects, as well as storage time $\times \mathrm{CO}_{2}, \mathrm{CO}_{2} \times 1-\mathrm{MCP}$ interactions $(P \leq 0.05$, ANOVA table not shown). At $2.5 \mathrm{kPa} \mathrm{CO}_{2}$ the concentrations of insoluble conjugated Spm in 1-MCP-treated fruit never exceeded $18 \%$ of those in control fruit over the 8 - to 46 -week period; however, at
$0.03 \mathrm{kPa} \mathrm{CO} 2$ the concentrations were $280-1250 \%$ greater at 8,14 , and 23 weeks (Figure 5D).

Regardless of 1-MCP and $\mathrm{CO}_{2}$ treatments GABA accumulated in a linear fashion over the storage period (Figure 6A), whereas glutamate declined after an initial rise (Figure 6B). Notably, fruit receiving $2.5 \mathrm{kPa} \mathrm{CO}_{2}$ and 1-MCP accumulated twice as much GABA $\left(\sim 2{\text { nmol } g^{-1} \text { FM week }}^{-1}\right)$ as fruit receiving $0.03 \mathrm{kPa} \mathrm{CO}_{2}$ only, accounting for approximately one half of the decline in glutamate over the same period. The GABA concentrations displayed significant storage time, $\mathrm{CO}_{2}$ and 1MCP main effects, as well as storage time $\times 1-\mathrm{MCP}$ interactions $(P \leq 0.05$, ANOVA table not shown). At 2.5 and $0.03 \mathrm{kPa}$ $\mathrm{CO}_{2}$ the GABA concentrations in 1-MCP-treated fruit were 19 and $25 \%$ greater, respectively, than those in control fruit at 33 weeks (Figure 6A). Glutamate showed significant storage time, $\mathrm{CO}_{2}$ and 1-MCP main effects, as well as storage time $\times 1$ MCP, $\mathrm{CO}_{2} \times 1-\mathrm{MCP}$ interactions $(P \leq 0.05$, ANOVA table not shown). At $2.5 \mathrm{kPa} \mathrm{CO} 2$ glutamate concentrations in 1-MCPtreated fruit were $34-38 \%$ greater than those in control fruit at 14 and 23 weeks, whereas at $0.03 \mathrm{kPa} \mathrm{CO}_{2}$ they were 8$57 \%$ greater than those in control fruit over the storage period (Figure 6B).

\section{DISCUSSION}

Both PAs and GABA appear to function in various physiological processes such as stress responses and growth and development (Alcázar etal., 2010; Fincato etal., 2012; Moschou et al., 2012; Shelp et al., 2012b,c). The presence and interconversion of free forms of Put, Spd and Spm have been the focus of PA research, but soluble (i.e., bound to small molecules such as phenolic acids) 

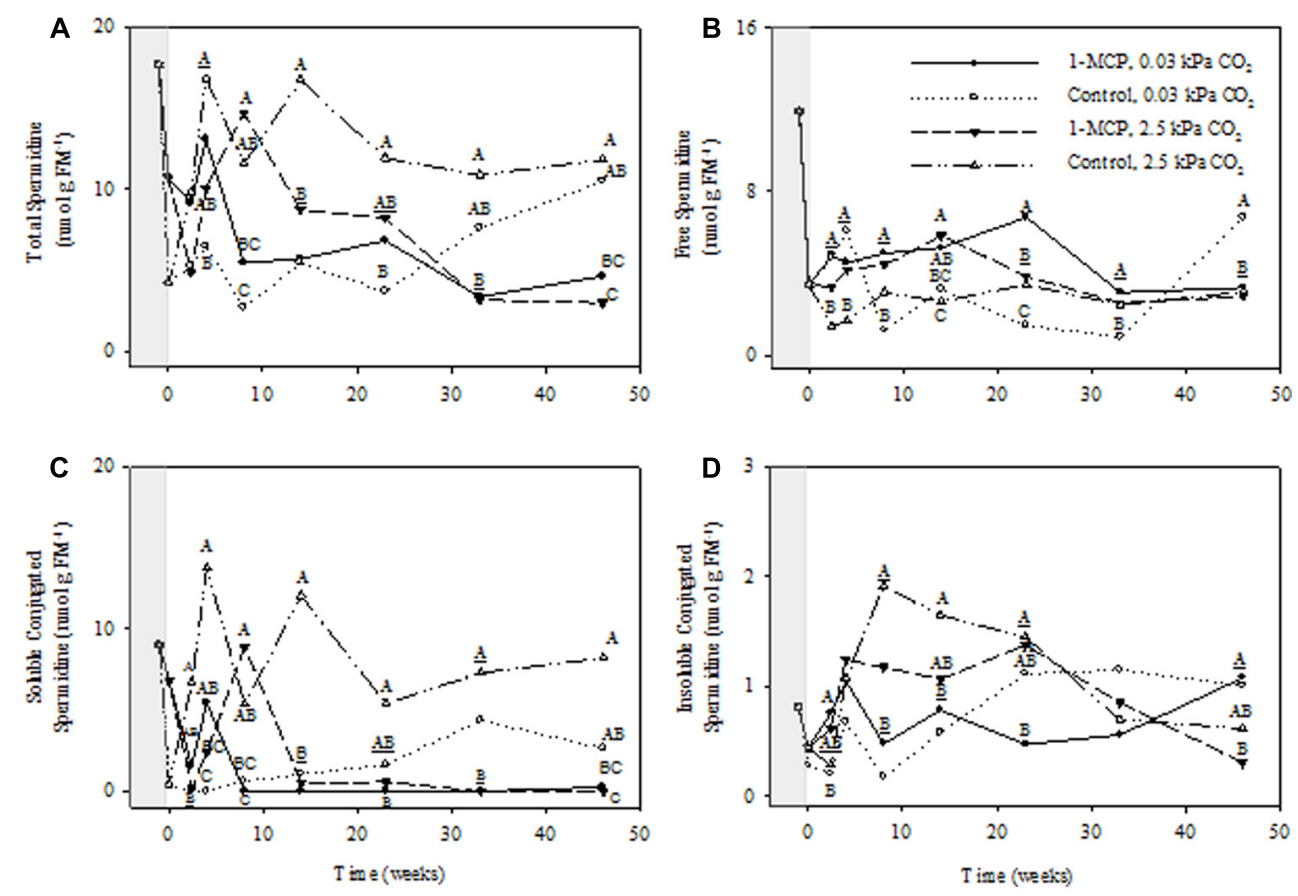

FIGURE 4 | Effects of 1-MCP and elevated $\mathrm{CO}_{2}$ on total (A), free (B), soluble conjugated (C), and insoluble conjugated (D) spermidine in "Empire" fruit during controlled atmosphere storage. With the exception of the beginning and end of 1-MCP treatment ( -1 day to 0 week, the shaded area), all data are mean estimates of four storage replicates. Different letter groupings indicate significant differences between treatments within weeks $(P \leq 0.05)$. Underlined letters indicate a shared letter for overlapping data; where letters are absent at a time point, there were no significant differences. and insoluble (i.e., bound to macromolecules such as nucleic acids and proteins) conjugated forms also exist. The ratios between free and conjugated PAs vary among plant species (Bagni and Tassoni, 2001), and some evidence exists for interconversion between free and conjugated PAs (Bassard et al., 2010), which could influence our interpretation of the impact of 1-MCP and CA on PAs and possibly GABA in apple fruit (Figure 1). Interestingly, it has been suggested that the stress hormone abscisic acid contributes to the conversion of conjugated forms of PA to the free forms (Ben Hassine et al., 2009).

In the present study, the concentrations of free and conjugated forms of PAs were determined in ripening 1-MCP-treated "Empire" apple fruit over a 46-week storage period under CA conditions. Initially, there were marked fluctuations in the concentrations of these PAs as the fruit acclimated to the shift in environmental conditions. Steady-state levels were evident after approximately 8 weeks of storage. It is well known that 1-MCP treatment should inhibit the autocatalytic production of ethylene in apple fruit (Pang et al., 2006; DeEll et al., 2008; Fawbush et al., 2008; Jung and Watkins, 2011), reduce the expression of genes involved in ethylene biosynthesis (Dal Cin et al., 2006; Pang et al., 2006; Vilaplana et al., 2007), and decrease the level of ACC (Bulens et al., 2012). However, we found no evidence for elevated levels of total PAs, Put, Spd, or Spm during the steady-state period (8-46 weeks) in response to 1-MCP treatment; indeed the levels tended to be lower regardless of $\mathrm{CO}_{2}$ (Figures 2-5), suggesting that the availability of SAM for PA biosynthesis in apple fruit was not influenced by the 1-MCP treatment. These findings are consistent with previous studies of ripening apple and tomato fruits, which suggest that the requirement for SAM in PA biosynthesis is not limited by the requirement in ethylene biosynthesis (Van de Poel et al., 2013; Lasanajak et al., 2014), and suggest an unknown biochemical or transcriptional mechanism, possibly altering the PA biosynthetic rates from glutamate (Alcázar et al., 2010; Majumdar et al., 2013), was responsible for the lower total PA levels in 1MCP-treated fruit under CA storage. However, these findings are at odds with the generally accepted view that PAs, especially Spd and Spm, accumulate in respond to abiotic stress (Groppa and Benavides, 2008; Bassard et al., 2010; Shelp et al., 2012c), which could be due to a variety of reasons: that view is generally based on free PA levels, rather than total PAs; apple fruit experience multiple stresses during CA storage; and, ripening apple fruit, like tomato fruit (Mattoo et al., 2010), are at a terminal developmental stage.

1-Methylcyclopropene application changed the levels of individual PAs and the relative proportions of free and conjugated forms. Total Put levels tended to be lower with 1-MCP regardless of the $\mathrm{CO}_{2}$ level, and while this was mostly at the expense of free Put, large transient increases in soluble conjugated Put were also evident (Figure 3). Total Spd levels tended to be lower with 1-MCP, particularly at $2.5 \mathrm{kPa} \mathrm{CO}_{2}$, and this was mostly at the expense of soluble conjugated Spd (Figure 4). Total Spm levels at $2.5 \mathrm{kPa} \mathrm{CO} 2$ tended to be lower with 1-MCP, and this was mostly at the expense of both soluble and insoluble conjugated Spm (Figure 5). Overall, total Spd and Spm levels at $0.03 \mathrm{kPa}$ were relatively unaffected, compared to $2.5 \mathrm{kPa} \mathrm{CO}_{2}$, but transient 

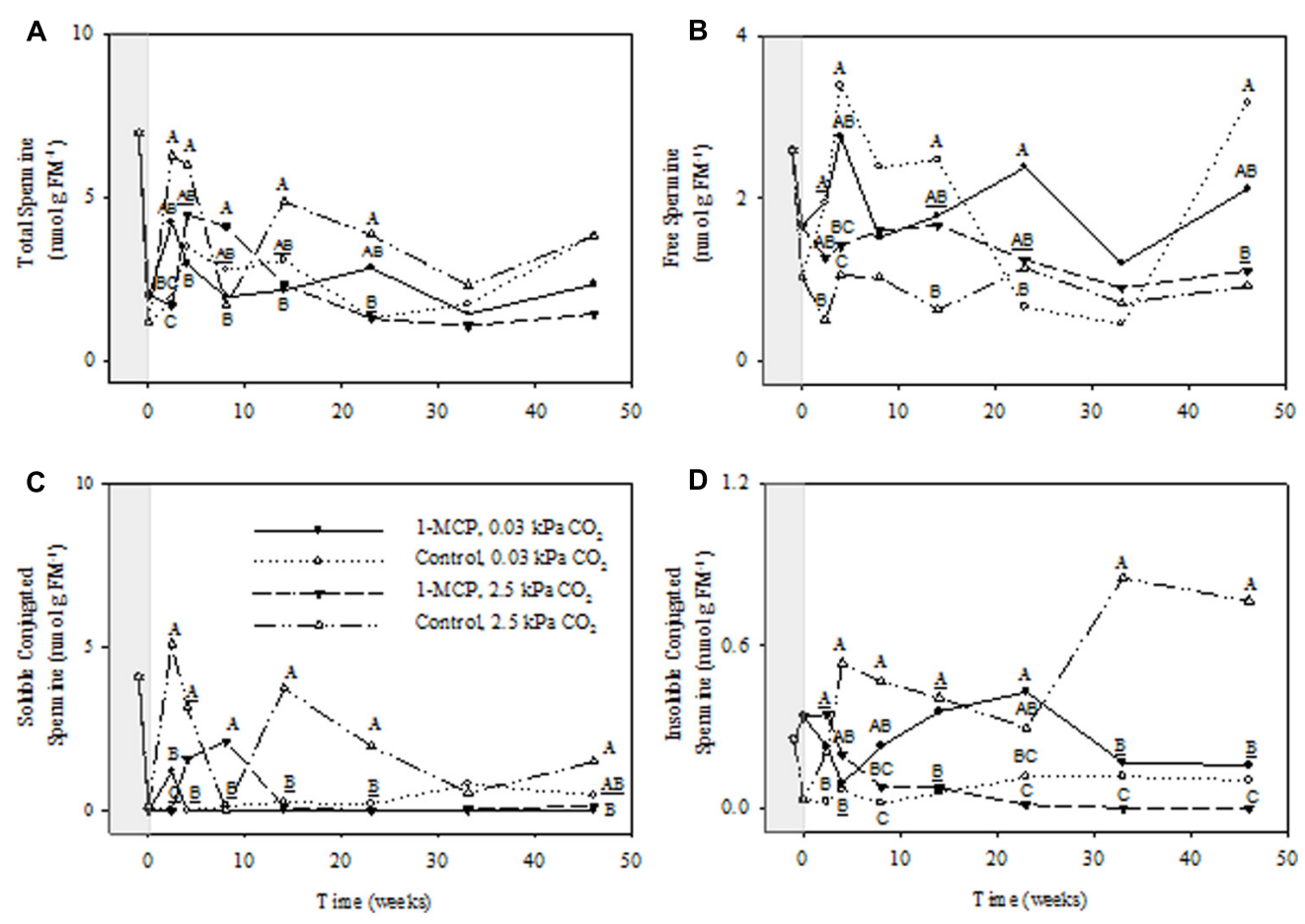

FIGURE 5 | Effects of 1-MCP and elevated $\mathrm{CO}_{2}$ on total (A), free (B), soluble conjugated (C), and insoluble conjugated (D) spermine in

"Empire" fruit during controlled atmosphere storage. With the exception of the beginning and end of 1-MCP treatment $(-1$ day to 0 week, the shaded area), all data are mean estimates of four storage replicates. Different letter groupings indicate significant differences between treatments within weeks $(P \leq 0.05)$. Underlined letters indicate a shared letter for overlapping data; where letters are absent at a time point, there were no significant differences. increases in free Spd and Spm were evident. Thus, 1-MCP treatment reduced the accumulation of individual PAs with elevated $\mathrm{CO}_{2}$ under CA conditions; however, there was a general decrease and increase in the ratio of free:conjugated forms for Put and Spd plus Spm, respectively. The accumulation of PAs was unaffected under low $\mathrm{CO}_{2}$, but there was some evidence for accumulation of conjugated Spd and Spm. Since total PA levels declined with 1MCP (Figure 2), this differential response of Put and Spd plus Spm in the partitioning between free and conjugated forms could not be attributed to altered SAM availability. The response might be attributed, at least in part, to changes in the conversion and backconversion of PAs, and the interconversion of free and conjugated forms in apple fruit, although the activities of polyamine oxidases (PAOs) could be limited by the low $\mathrm{O}_{2}$ status of intact apple fruit stored under CA conditions (Ho et al., 2011; Shelp et al., 2012c).

Glutamate serves a precursor for biosynthesis of both GABA and PAs, raising the possibility that GABA in CA-stored apple fruit can be derived directly from glutamate or indirectly from free Put or free Spd (Figure 1). Regardless of 1-MCP and $\mathrm{CO}_{2}$ treatments, the availability of glutamate showed a transient peak initially, probably due to protein degradation (Magné et al., 1997; Sugimoto et al., 2011), and this was followed by a steady decline over the remainder of the storage period which coincided with accumulating GABA (Figure 6). This pattern could be attributed due to the stimulation of glutamate decarboxylase $(\mathrm{GAD})$ activities via bound $\mathrm{Ca}^{2+} /$ calmodulin or lower cytosolic pH (Shelp etal., 2012a; Trobacher et al., 2013b), and product inhibition of GABA transaminase activity (Clark et al., 2009) due to the restricted activity of succinic semialdehyde dehydrogenase activity under $\mathrm{O}_{2}$ deficiency (Busch and Fromm, 1999; Shelp etal., 1999). GABA accumulation was lowest at $0.03 \mathrm{kPa} \mathrm{CO}$ and noticeably greater with either 1-MCP or $2.5 \mathrm{kPa}$ $\mathrm{CO}_{2}$. These findings are consistent with previous research showing that GABA accumulates in tissues of "Empire" apple fruit during $\mathrm{CA}$ storage with elevated $\mathrm{CO}_{2}$ and is then catabolized when the fruit are transferred to ambient conditions (Deewatthanawong and Watkins, 2010; Lee et al., 2012; Trobacher et al., 2013a). Relatively higher levels of free Put and Spd than free Spm are also consistent with studies of other species and tissues (Mattoo et al., 2010). Interestingly, the changing levels of Spd seemed to be more highly correlated than those of Put with the rate of GABA production regardless of the 1-MCP and $\mathrm{CO}_{2}$ treatments, suggesting that Spd could be in steadystate equilibrium with GABA. It has been argued that changes in $\mathrm{O}_{2}$ availability and cellular redox balance in apple fruit stored under CA conditions would directly influence the activity of 4-aminobutyraldehyde dehydrogenase, as well as diamine oxidases (DAO), thereby restricting GABA formation from both Spd and Put (Shelp et al., 2012c). Unfortunately, pool sizes do not indicate the flux through a pathway, mutants of the metabolic routes for GABA and PAs are not readily available for apple, and radiolabelled precursors cannot be supplied to intact apples without perturbing the internal gaseous environment, which would most certainly affect GABA formation from glutamate. Useful 

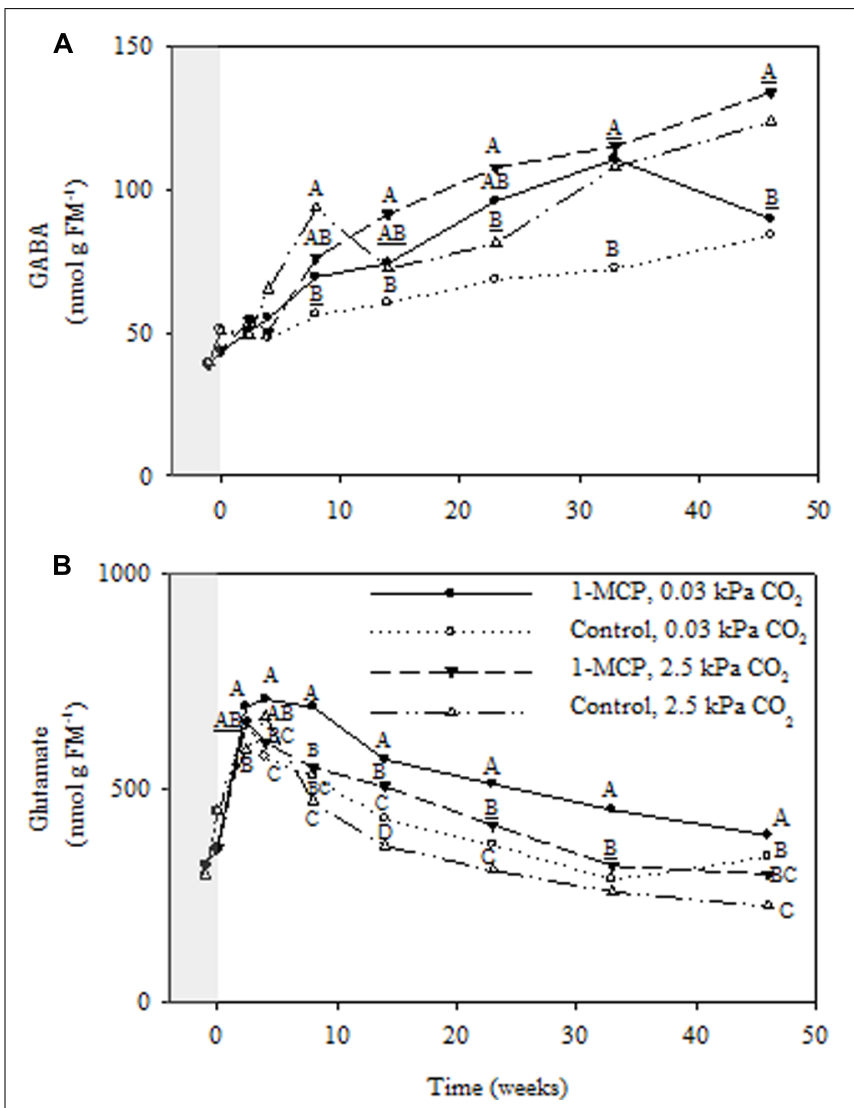

FIGURE 6 | Effects of 1-MCP and elevated $\mathrm{CO}_{2}$ on GABA (A) and glutamate (B) levels in "Empire" fruit during controlled atmosphere storage. With the exception of the beginning and end of 1-MCP treatment ( -1 day to 0 week, the shaded area), all data are mean estimates of four storage replicates. Different letter groupings indicate significant differences between treatments within weeks $(P \leq 0.05)$. Underlined letters indicate a shared letter for overlapping data; where letters are absent at a time point, there were no significant differences.

information about the relative contributions of glutamate and PAs to GABA production in intact apple fruit could be gained via a combination of metabolite and gene transcript analyses. Recently, use of the DAO inhibitor aminoguanidine suggested that approximately $30 \%$ of the GABA accumulated in fava bean seed germinating under hypoxia is derived from PAs (Yang et al., 2013). Notably, the free levels of the three PAs, especially Put, increased, unlike the case reported here, and this was accompanied by some loss of GAD activity, which was attributed to growth inhibition.

While uncertainty continues regarding the relationship between PA and ethylene biosynthesis in fruits, especially those exposed to multiple abiotic stresses, our research indicates that the requirement for SAM in PA biosynthesis in CA-stored apple fruit was probably not limited by the requirement in ethylene biosynthesis. Moreover, the differential response of PA partitioning between free and conjugated forms could be attributed to changes in the interconversion of free and conjugated forms and the conversion and back-conversion of PAs. Also, the data could be interpreted as preliminary evidence for a relationship between Spd level and GABA production, but it is argued that the biochemical reactions involved would be limited by the in vivo $\mathrm{O}_{2}$ level, and that elevated GAD activity and product inhibition of GABA transaminase activity would be responsible for GABA accumulation in these fruit.

\section{ACKNOWLEDGMENTS}

The authors thank Dr. Gordon J. Hoover for technical assistance with HPLC analysis. The financial support of the Natural Sciences and Engineering Research Council (NSERC) of Canada (Strategic Project and Individual Discovery Grants), the Ontario Ministry of Agriculture Food and Rural Affairs, and Rohm and Haas Canada LP (AgroFresh Inc.) is gratefully acknowledged.

\section{REFERENCES}

Alcázar, R., Altabella, T., Marco, F., Bortolotti, C., Reymond, M., Koncz, C., et al. (2010). Polyamines: molecules with regulatory functions in plant abiotic stress tolerance. Planta 231, 1237-1249. doi: 10.1007/s00425-010-1130-0

Allan, W. L., and Shelp, B. J. (2006). Fluctuations of $\gamma$-aminobutyrate, $\gamma$ hydroxybutyrate, and related amino acids in Arabidopsis leaves as a function of the light-dark cycle, leaf age, and N stress. Can. J. Bot. 84, 1339-1346. doi: 10.1139/b06-093

Bagni, N., and Tassoni, A. (2001). Biosynthesis, oxidation and conjugation of aliphatic polyamines in higher plants. Amino Acids 20, 301-317. doi: $10.1007 / \mathrm{s} 007260170046$

Bassard, J. E., Ullmann, P., Bernier, F., and Werck-Reichhart, D. (2010). Phenolamides: bridging polyamines to the phenolic metabolism. Phytochemistry 71, 1808-1824. doi: 10.1016/j.phytochem.2010.08.003

Ben Hassine, A., Ghanem, M. E., Bouzid, S., and Lutts, S. (2009). Abscisic acid has contrasting effects on salt excretion and polyamine concentrations of an inland and a coastal population of the Mediterranean xero-halophyte species Atriplex halimus. Ann. Bot. 104, 925-936. doi: 10.1093/aob/mcp174

Bitrián, M., Zarza, X., Altabella, T., Tiburico, A. F., and Alcázar, R. (2012). Polyamines under abiotic stress: metabolic crossroads and hormonal crosstalks in plants. Metabolites 2, 516-528. doi: 10.3390/metabo2030516

Bulens, B., Van de Poel, B., Hertog, M. L. A. T. M., De Proft, M. P., Geeraerd, A. H., and Nicolai, B. M. (2012). Influence of harvest time and 1-MCP application on postharvest ripening and ethylene biosynthesis of 'Jonagold' apple. Postharvest Biol. Technol. 72, 11-19. doi: 10.1016/j.postharvbio.2012.05.002

Busch, K. B., and Fromm, H. (1999). Plant succinic semialdehyde dehydrogenase. Cloning, purification, localization in mitochondria, and regulation by adenine nucleotides. Plant Physiol. 121, 589-597. doi: 10.1104/pp.121.2.589

Chen, T., Xu, Y., Wang, J., Wang, Z., Yang, J., and Zhang, J. (2013). Polyamines and ethylene interact in rice grains in response to soul drying during grain filling. $J$. Exp. Bot. 64, 2523-2538. doi: 10.1093/jxb/ert115

Clark, S. M., Di Leo, R., Dhanoa, P. K., Van Cauwenberghe, O. R., Mullen, R. T., and Shelp, B. J. (2009). Biochemical characterization, mitochondrial localization, expression, and potential functions for an Arabidopsis $\gamma$-aminobutyrate transaminase that utilizes both pyruvate and glyoxylate. J. Exp. Bot. 60, 1743-1757. doi: 10.1093/jxb/erp044

Dal Cin, V., Rizzini, F. M., Botton, A., and Tonutti, P. (2006). The ethylene biosynthetic and signal transduction pathways are differently affected by 1MCP in apple and peach fruit. Postharvest Biol. Technol. 42, 125-133. doi: 10.1016/j.postharvbio.2006.06.008

DeEll, J., Ayres, J., and Murr, D. (2008). 1-Methylcyclopropene concentration and timing of postharvest application alters the ripening of 'McIntosh' apples during storage. Horttechnology 18, 624-630.

Deewatthanawong, R., and Watkins, C. B. (2010). Accumulation of $\gamma$-aminobutyric acid in apple, strawberry and tomato fruit in response to postharvest treatments. Acta Hortic. 877, 947-952.

Fawbush, F., Nock, J. F., and Watkins, C. B. (2008). External carbon dioxide injury and 1-methylcyclopropene (1-MCP) in the 'Empire' apple. Postharvest Biol. Technol. 48, 92-98. doi: 10.1016/j.postharvbio.2007.09.005

Fincato, P., Moschou, P. N., Ahou, A., Angelini, R., Roubelakis, K. A., Federico, R., et al. (2012). The members of Arabidopsis thaliana PAO gene family exhibit 
distinct tissue- and organ-specific expression pattern during seedling growth and flower development. Amino Acids 42, 831-841. doi: 10.1007/s00726-011-0999-7

Gennaro, M. C., Mentasti, E., Sarzanini, C., and Porta, V. (1988). Aliphatic monoamines, diamines, polyamines: an HPLC method for their identification and separation by a dansylation reaction; the study of separation factors in homologous series. Chromatographia 25, 117-124. doi: 10.1007/BF02259027

Groppa, M. D., and Benavides, M. P. (2008). Polyamines and abiotic stress: recent advances. Amino Acids 34, 35-43. doi: 10.1007/s00726-007-0501-8

Gupta, A., Pal, R. K., and Rajam, M. V. (2013). Delayed ripening and improved fruit processing in tomato by RNAi-mediated silencing of three homologs of 1aminopropane-1-carboxylate synthase gene. J. Plant Physiol. 170, 987-995. doi: 10.1016/j.jplph.2013.02.003

Ho, Q. T., Verboven, P., Verlinden, B. E., Herremans, E., Wevers, M., Carmeliet, J., et al. (2011). A three dimensional multiscale model for gas exchange in fruit. Plant Physiol. 155, 1158-1168. doi: 10.1104/pp.110.169391

Jung, S. K., and Watkins, C. B. (2011). Involvement of ethylene in browning development of controlled atmosphere-stored 'Empire' apple fruit. Postharvest Biol. Technol. 59, 219-226. doi: 10.1016/j.postharvbio.2010.08.019

Lasanajak, Y., Minocha, R., Minocha, S. C., Goyal, R., Fatima, T., Handa, A. K., et al (2014). Enhanced flux of substrates into polyamine but not ethylene in tomato fruit engineered with yeast $S$-adenosylmethionine decarboxylase gene. Amino Acids 46, 729-742. doi: 10.1007/s00726-013-1624-8

Lee, J., Rudell, D. R., Davies, P. J., and Watkins, C. B. (2012). Metabolic changes in 1-methylcyclopropene (1-MCP)-treated 'Empire' apple fruit during storage. Metabolomics 8, 742-753. doi: 10.1007/s11306-011-0373-5

Magné, C., Bonenfant-Magné, M., and Audran, J.-C. (1997). Nitrogenous indicator of postharvest ripening and senescence in apple fruit (Malus domestica Borkh. cv. Granny Smith). Int. J. Plant Sci. 158, 811-817. doi: 10.1086/297494

Majumdar, R., Shao, L., Miocha, R., Long, S., and Minocha, S. C. (2013). Ornithine: the overlooked molecule in the regulation of polyamine metabolism. Plant Cell Physiol. 54, 990-1004. doi: 10.1093/pcp/pct053

Mattoo, A. K., Minocha, S. C., Minocha, R., and Handa, A. K. (2010). Polyamines and cellular metabolism in plants: transgenic approaches reveal different responses to diamine putrescine versus higher polyamines spermidine and spermine. Amino Acids 38, 405-413. doi: 10.1007/s00726-009-0399-4

Moschou, P. N., Wu, J., Cona, A., Tavladoraki, P., Angelini, R., and RoubelakisAngelakis, K. A. (2012). The polyamines and their catabolic products are significant players in the turnover of nitrogenous molecules in plants. J. Exp. Bot. 63, 5003-5015. doi: 10.1093/jxb/ers202

Pang, X.-M., Nada, K., Liu, J.-H., Kitashiba, H., Honda, C., Yamashita H., et al. (2006). Interrrelationships between polyamine and ethylene in 1methylcycopropene treated apple fruits after harvest. Physiol. Plant. 128, 351-359. doi: 10.1111/j.1399-3054.2006.00748.x

Shelp, B. J., Bown, A. W., and McLean, M. D. (1999). Metabolism and functions of gamma-aminobutyric acid. Trends Plant Sci. 4, 446-452. doi: 10.1016/S13601385(99)01486-7

Shelp, B. J., Bozzo, G. G., Trobacher, C. P., Chiu, G., and Bajwa, V. S. (2012a). Strategies and tools for studying the metabolism and function of $\gamma$-aminobutyrate in plants: I. Pathway structure. Botany 90, 651-668. doi: 10.1139/b2012-030

Shelp, B. J., Bozzo, G. G., Zarei, A., Simpson, J. P., Trobacher, C. P., and Allan, W. L. (2012b). Strategies and tools for studying the metabolism and function of $\gamma$-aminobutyrate in plants: II. Integrated analysis. Botany 90, 781-793. doi: 10.1139/b2012-041
Shelp, B. J., Bozzo, G. G., Trobacher, C. P., Zarei, A., Deyman, K. L., and Brikis, C. J. (2012c). Hypothesis/review: contribution of putrescine to 4-aminobutyrate (GABA) production in response to abiotic stress. Plant Sci. 193-194, 130-135. doi: 10.1016/j.plantsci.2012.06.001

Shiozaki, S., Ogata, T., and Horiuchi, S. (2000). Endogenous polyamines in the pericap and seed of the grape berry during development and ripening. Sci. Hortic. 83, 33-41. doi: 10.1016/S0304-4238(99)00064-3

Smith, M. A., and Davies, P. J. (1985). Separation and quantitation of polyamines in plant tissue by high performance liquid chromatography of their dansyl derivatives. Plant Physiol. 78, 89-91. doi: 10.1104/pp.78.1.89

Sugimoto, N., Jones, A. D., and Beaudry, R. (2011). Changes in free amino acid content in 'Jonagold' apple fruit as related to branched-chain ester production, ripening and senescence. J. Am. Soc. Hortic. Sci. 136, 429-440.

Trobacher, C. P., Clark, S. M., Bozzo, G. G., Mullen, R. T., DeEll, J. R., and Shelp, B. J. (2013a). Catabolism of GABA in apple fruit: subcellular localization and biochemical characterization of two $\gamma$-aminobutyrate transaminases. Postharvest Biol. Technol. 75, 106-113. doi: 10.1016/j.postharvbio.2012.08.005

Trobacher, C. P., Zarei, A., Liu, J., Clark, S. M., Bozzo, G. G., and Shelp, B. J. (2013b). Calmodulin-dependent and calmodulin-independent glutamate decarboxylases in apple fruit. BMC Plant Biol. 13:144. doi: 10.1186/1471-2229-13-144

Van de Poel, B., Bulens, I., Oppermann, Y., Hertog, M. L. A. T. M., Nicolai, B. M., Sauter, M., etal. (2013). S-adenosyl-L-methionine usage during climacteric ripening of tomato in relation to ethylene and polyamine biosynthesis and transmethylation capacity. Physiol. Plant. 148, 176-188. doi: 10.1111/j.1399-3054.2012.01703.x

Vilaplana, R., Soria, Y., Valentines, M. C., and Larrigaudière, C. (2007). Specific response of apple skin and pulp tissues to cold stress and 1-MCP treatment. Postharvest Biol Technol. 43, 215-220. doi: 10.1016/j.postharvbio.2006. 09.003

Watkins, C. B. (2006). The use of 1-methylcyclopropene (1-MCP) on fruits and vegetables. Biotechnol. Adv. 24, 389-409. doi: 10.1016/j.biotechadv.2006.01.005

Watkins, C. B. (2008). Overview of 1-methylcyclopropene trials and uses for edible horticultural crops. HortScience 43, 86-94.

Yang, R., Guo, Q., and Gu, Z. (2013). GABA shunt and polyamine degradation pathway $\gamma$-aminobutyric acid accumulation in germinating fava bean (Vicia faba L.) under hypoxia. Food Chem. 136, 152-159. doi: 10.1016/j.foodchem.2012.08.008

Conflict of Interest Statement: This research was funded in part by AgroFresh Inc., the manufacturer of SmartFresh ${ }^{\mathrm{SM}}$.

Received: 11 January 2014; accepted: 25 March 2014; published online: 10 April 2014. Citation: Deyman KL, Brikis CJ, Bozzo GG and Shelp BJ (2014) Impact of 1-methylcyclopropene and controlled atmosphere storage on polyamine and 4aminobutyrate levels in "Empire" apple fruit. Front. Plant Sci. 5:144. doi: 10.3389/fpls.2014.00144

This article was submitted to Plant Metabolism and Chemodiversity, a section of the journal Frontiers in Plant Science.

Copyright (C) 2014 Deyman, Brikis, Bozzo and Shelp. This is an open-access article distributed under the terms of the Creative Commons Attribution License (CC BY). The use, distribution or reproduction in other forums is permitted, provided the original author(s) or licensor are credited and that the original publication in this journal is cited, in accordance with accepted academic practice. No use, distribution or reproduction is permitted which does not comply with these terms. 